\title{
Cross-Cultural Adaptation and Validation of the Malay Satisfaction Questionnaire for Osteoporosis Prevention in Malaysia
}

\author{
Anisha Kaur Sandhu $\mathbb{1}^{1,2}$ \\ Li Shean Toh ${ }^{3}$ \\ Yew Kong Lee' \\ Alexander Tong Boon Tan ${ }^{4,5}$ \\ Jeyakantha Ratnasingam ${ }^{5}$ \\ Nagammai Thiagarajan ${ }^{6}$ \\ Pauline Siew Mei Lai (D) \\ 'Department of Primary Care Medicine, \\ Faculty of Medicine, University of Malaya, \\ Kuala Lumpur, Malaysia; ${ }^{2}$ School of \\ Pharmacy, Monash University Malaysia, \\ Bandar Sunway, Selangor, Malaysia; \\ ${ }^{3}$ School of Pharmacy, University of \\ Nottingham, Nottingham, UK; ${ }^{4}$ Sunway \\ Medical Centre, Bandar Sunway, Malaysia; \\ ${ }^{5}$ Department of Medicine \\ (Endocrinology), University of Malaya, \\ Kuala Lumpur, Malaysia; ${ }^{6}$ Kuala Lumpur \\ Health Clinic, Ministry of Health Malaysia, \\ Kuala Lumpur, Malaysia
}

Correspondence: Pauline Siew Mei Lai Department of Primary Care Medicine, Faculty of Medicine, Jalan Profesor Diraja Ungku Aziz, University Malaya, Wilayah Persekutuan Kuala Lumpur, 50603, Malaysia

Tel $+603-79492802$

Fax +603-794924368

Email plai@ummc.edu.my
Purpose: The English Satisfaction Questionnaire for Osteoporosis Prevention (SQOP) is validated in Malaysia. However, Malay is the national language of Malaysia spoken by the majority of Malaysians. The aim of this study was to cross-culturally adapt and validate the Malay Satisfaction Questionnaire for Osteoporosis Prevention (SQOP-M) in Malaysia.

Patients and Methods: This study was carried out from March to October 2018 at a tertiary hospital in Kuala Lumpur. The SQOP was translated from English to Malay according to international guidelines. Malay-speaking postmenopausal women $\geq 50$ years were recruited and randomized into control and intervention groups. The intervention group received an osteoporosis prevention information booklet and a 15-minute pharmacist counselling session. All patients were asked to answer the SQOP-M questionnaire at baseline and two weeks later. The control group received the intervention after the study was completed. Results: Overall, $230 / 348$ patients were recruited $(\mathrm{C}=115$, $\mathrm{I}=115$, response rate $=66.1 \%)$. Exploratory factor analysis extracted four domains. Cronbach's $\alpha$ ranged from 0.230 to 0.938 . Kappa measurement of agreement values ranged from 0.124 to 0.627 , where $10 / 23$ (43.5\%) items were in moderate to substantial agreement. Wilcoxon signed rank test values were statistically significant $(\mathrm{p}<0.005)$ for $4 / 23$ items. Item 17 was an optional question and excluded from analysis. Total satisfaction score was significantly higher for intervention group patients [76.9 (47.6-53.9) vs 50.4 (47.6-53.9), $\mathrm{p}<0.001]$ indicating higher satisfaction compared to control group.

Conclusion: The SQOP-M was found to be valid and reliable in assessing patient satisfaction of osteoporosis screening and prevention services provided to Malay-speaking patients in Malaysia.

Keywords: Malaysia, osteoporosis, patient satisfaction, validation study

\section{Introduction}

Patient satisfaction is an important parameter to assess the quality of healthcare service delivery as it provides feedback and evaluation of services experienced by patients, ensures accountability among healthcare professionals and continued improvement in service delivery to meet patient needs. ${ }^{1-3}$ Research has linked osteoporosis treatment effectiveness to patient satisfaction for postmenopausal women; as women showed better persistence to their osteoporosis treatment when satisfied. ${ }^{4,5}$ Studies show that satisfied patients experience better patient-healthcare provider relationships, use health services more consistently, and register an improvement in clinical outcomes due to increased adherence to medical advice, treatments and medications. ${ }^{1-3}$ 
Osteoporosis is underdiagnosed due to its asymptomatic nature and affects 1 in 4 women aged above 45 years in Malaysia. ${ }^{6-8}$ Osteoporosis can have debilitating consequences when it causes an osteoporotic fracture. Patients suffer from pain, loss of mobility and independence, and increased mortality. In addition, health costs increase drastically due to hospitalization and rehabilitation. ${ }^{6,8-10}$ Malaysia is projected to have the highest increase in hip fracture incidence when compared to other Asian countries due to its ageing population. ${ }^{11-13}$ Hence, osteoporosis poses a serious medical concern for Malaysian healthcare.

Prevention is a key method in managing osteoporosis and fragility fractures. ${ }^{14}$ Prevention relies heavily on a patient's motivation to frequent osteoporosis services provided, self-manage anti-osteoporotic medications and adhere to lifestyle advice on diet, supplementation and exercise. ${ }^{7,15,16}$ It is therefore important to ensure that patients receive osteoporosis services that they are satisfied with so they continue to engage with their healthcare providers, attend clinic appointments and comply with treatment.

Currently, there are three tools that assess patient satisfaction in relation to osteoporosis including the Osteoporosis Patient Treatment Satisfaction Questionnaire (OPSAT-Q), ${ }^{17}$ and the Preference and Satisfaction Questionnaire (PSQ), ${ }^{18}$ which were developed in the United States, as well as the Osteoporosis Patient Satisfaction Questionnaire (OPSQ) which was developed in Malaysia. ${ }^{19}$ These osteoporosis satisfaction tools were developed in English and focus mainly on assessing patient satisfaction towards osteoporosis and its treatment. The SQOP however, focuses on evaluating patient satisfaction towards osteoporosis screening and prevention services in Malaysia. ${ }^{2}$

The SQOP was developed and validated in English to assess patient satisfaction towards osteoporosis screening and prevention services provided by pharmacists in Malaysia. ${ }^{2}$ It was modified from the OPSQ and developed based on findings from a qualitative study assessing barriers and needs for an osteoporosis screening and prevention service in Malaysia. ${ }^{19}$ The SQOP can be used in any clinical setting. ${ }^{2,19}$ However, in Malaysia, osteoporosisrelated services are usually provided in hospitals with hospital pharmacists involved in providing osteoporosisrelated patient education. ${ }^{2,19}$

As Malay is the national language of Malaysia and widely spoken amongst Malaysians, a need was identified to cross-culturally adapt and validate the SQOP in Malay language. Additionally, this study shows global significance as Malay is an Austronesian language widely spoken by more than 200 million people in the South East Asian region. ${ }^{20}$ Therefore, Malay-speaking patients will be able to use this instrument to evaluate their satisfaction regarding osteoporosis screening and prevention services received. This will allow healthcare professionals in this region to continuously improve the quality of osteoporosis screening and prevention services provided, tailoring it to patient needs and preferences. Overall, this may lead to better engagement from osteoporotic patients as they are more satisfied with the services provided. This study also outlines clear processes for conducting a validation study for the SQOP which can be replicated easily for researchers in other countries to validate the SQOP for use in their native regions and languages. This will allow for osteoporosis prevention and screening services to be assessed globally using the SQOP measure.

\section{Patients and Methods}

\section{Aim of the Study}

This study aimed to cross-culturally adapt and validate the SQOP in the Malay language (SQOP-M) among postmenopausal women in Malaysia. This study was divided into two phases: the cross-cultural adaptation of the Malay Satisfaction Questionnaire for Osteoporosis Prevention (SQOP-M) and its validation.

\section{Phase I: The Cross-Cultural Adaptation of the Satisfaction Questionnaire for Osteoporosis Prevention (SQOP) from English to Malay}

During the content validity process, the SQOP was translated from English to Malay according to guidelines by The Professional Society for Health Economics and Outcomes Research (ISPOR). ${ }^{21,22}$ This process is illustrated in Figure 1.

The translated versions were reviewed and reconciled by an expert panel consisting of a doctor and three pharmacists with clinical experience who were fluent in English and Malay. The expert panel ensured that the meaning of the instrument was maintained during the forward (versions 1a and 1b) and backward (versions 3a and $3 \mathrm{~b}$ ) translation process. The final version (version 4) of the Malay SQOP (SQOP-M) was piloted amongst 10 postmenopausal women who spoke and understood Malay 


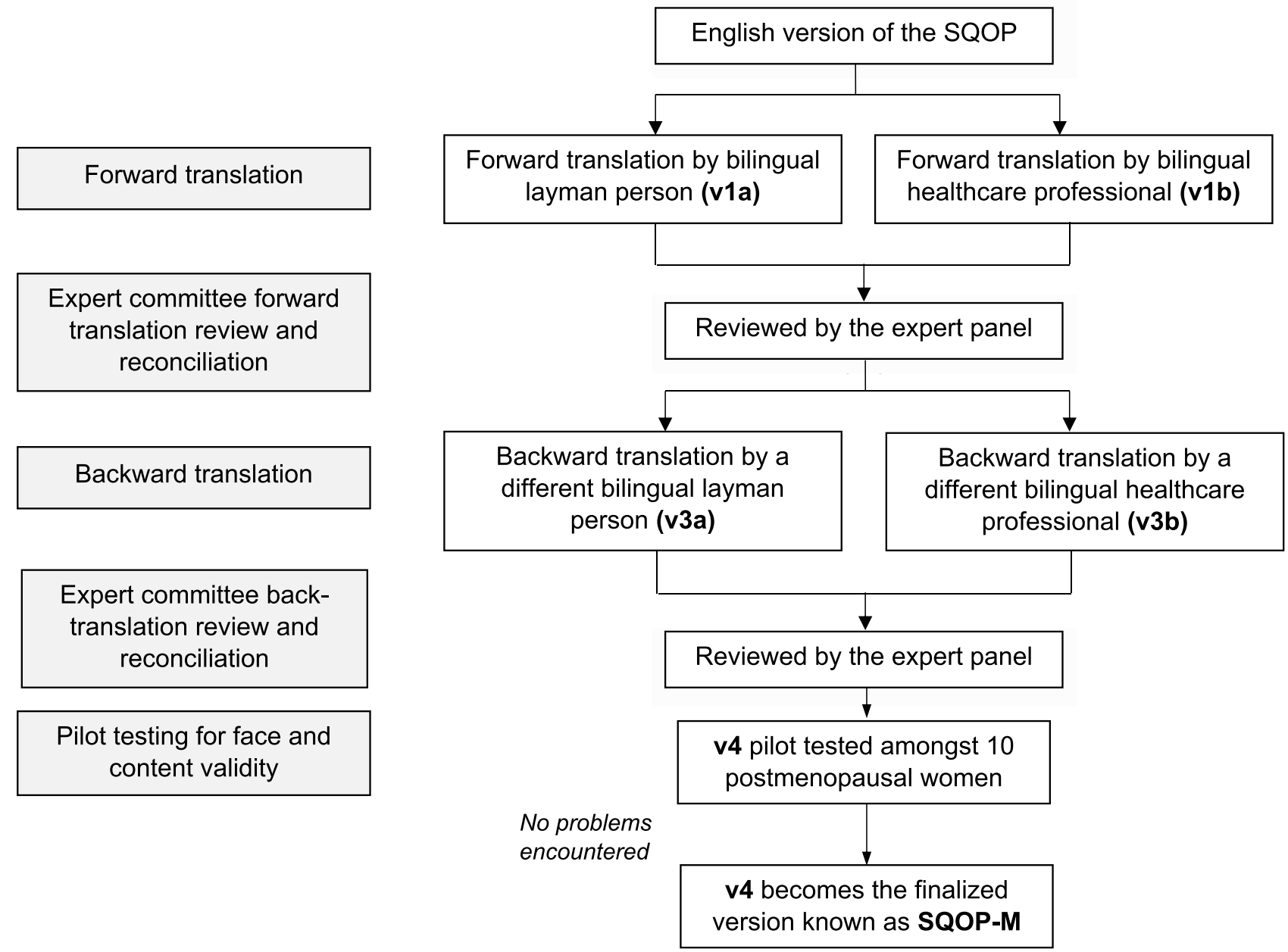

Figure I Translation process following the ISPOR guidelines.

to assess for face and content validity. ${ }^{22}$ They were asked for their views regarding the phrasing, formatting and content of the instrument but did not encounter problems in answering the questionnaire. ${ }^{22}$ Hence, version 4 was finalized.

\section{Phase 2: The Validation of the Malay Satisfaction Questionnaire for Osteoporosis Prevention (SQOP-M)}

This prospective validation study was conducted from March 2018 to October 2018 at a primary care clinic located within a tertiary hospital in Kuala Lumpur, Malaysia.

\section{Patients}

Postmenopausal women aged $\geq 50$ years who understood Malay were recruited. For the purpose of this study, postmenopausal was defined as having experienced a period of 12 consecutive months without menstruation after menopause. Patients were required to self-report and confirm if they were postmenopausal when screened by researchers. Any patient with a prior diagnosis of osteoporosis or who had a recent bone mineral density (DXA) scan $(<2$ years $)$ were excluded.

\section{Randomization}

Patients were randomized into two groups (control and intervention) to assess the discriminative validity of the SQOP-M. They were asked to draw a piece of paper from an envelope containing pieces of blue and pink paper. If the patient selected a blue piece of paper, she was allocated to the control group, whilst those selecting the pink piece of paper were allocated to the intervention group.

\section{Sample Size}

Sample size was calculated based on a 10:1 patient ratio to calculate factor analysis. ${ }^{23}$ The SQOP-M consisted of 23 items. Therefore, the total number of patients required was 
230. This would include 115 patients in the control group and 115 patients in the intervention group.

\section{Instruments Used}

A baseline demographic questionnaire was used to assess baseline demographics such as age, weight, education and income level for both the control and intervention group.

\section{The Malay Satisfaction Questionnaire for Osteoporosis Prevention (SQOP-M)}

The SQOP-M consists of two domains: clinical services (18 items) and types of counselling (5 items). Each item consists of a statement that may be answered using a 5-point Likert scale. One indicated the lowest satisfaction with that item whereas five indicated the highest satisfaction with that item. The SQOP-M score was calculated by summing the scores of all items, and converting to a percentage from $0-100$. The scores from each domain were also analyzed and summed up to provide the final domain score. A higher score indicated higher patient satisfaction with the osteoporosis services provided.

\section{Intervention}

The intervention consisted of patients receiving an osteoporosis prevention information booklet in Malay language as well as a 15-minute pharmacist-provided counselling session using the osteoporosis prevention information booklet which covered different lifestyle measures to prevent osteoporosis (dietary, supplementation, exercise and fall prevention strategies). ${ }^{24}$ Patients were also able to clarify any further questions they had regarding osteoporosis and its prevention after the counselling session.

Control patients received standard care which involved a regular visit to the doctor. Any counselling provided by the doctor would be at the doctor's discretion.

\section{Procedure}

Patients were approached individually by the researcher using the convenience sampling method whilst they were waiting to see their doctor. The convenience sampling method was used to accommodate for large volumes of patients in the primary care clinics and inconsistency of waiting times. The scattered seating layout of the primary care clinic with five different waiting areas across two floors also made it difficult to follow a systematic sampling process to approach patients at fixed periodic intervals due to difficulty in locating patients.
The purpose of the study was explained to patients who fulfilled eligibility criteria using the participant information sheet. For those who agreed to participate, written informed consent was obtained. Patients were informed that they could withdraw at any point if they felt uncomfortable or did not wish to continue. Baseline demographic information was obtained from the patients. Patients were then randomized to either the control or intervention group. The study procedure is further illustrated in Figure 2.

The SQOP-M questionnaire was administered to all patients at baseline. However, the intervention group patients received the intervention before the SQOP$\mathrm{M}$ was administered at baseline. For patients who had difficulty reading the questions, the researcher assisted the patients in answering SQOP-M questions. The completed questionnaires were checked by the researcher to ensure that all questions had been answered.

The SQOP-M questionnaire was administered again two weeks later via phone for test-retest reliability assessment. The questionnaire was retested after two weeks as this time interval is accepted to be long enough so participants are unable to recall their original responses while still retaining knowledge of the subject they were tested on. ${ }^{25,26}$ The control group received the intervention after the study had ended to ensure equity among both groups.

\section{Ethics Approval}

This study was approved by the Medical Research Ethics Committee of University Malaya Medical Centre (MREC ID NO: 2018115-5959) and the Medical Research Ethics Committee, Ministry of Health Malaysia (NMRR-181302-40112). This study was conducted in accordance with the Declaration of Helsinki.

\section{Data Analyses}

All data was entered into the IBM Statistical Package for the Social Sciences (SPSS) version 21 (IBM Corp, Armonk, NY). As normality could not be assumed, nonparametric tests were used. Continuous data was presented as median and interquartile range (IQR), whilst proportions were presented as number and percentage.

\section{Factor Analysis}

Confirmatory factor analysis (CFA) is used to confirm or reject hypothesized relationships based on theoretical constructs that are well understood for existing instruments, while exploratory factor analysis (EFA) is used to explore the patterns of a new tool to understand how different items and constructs relate to one another. ${ }^{27}$ EFA was 

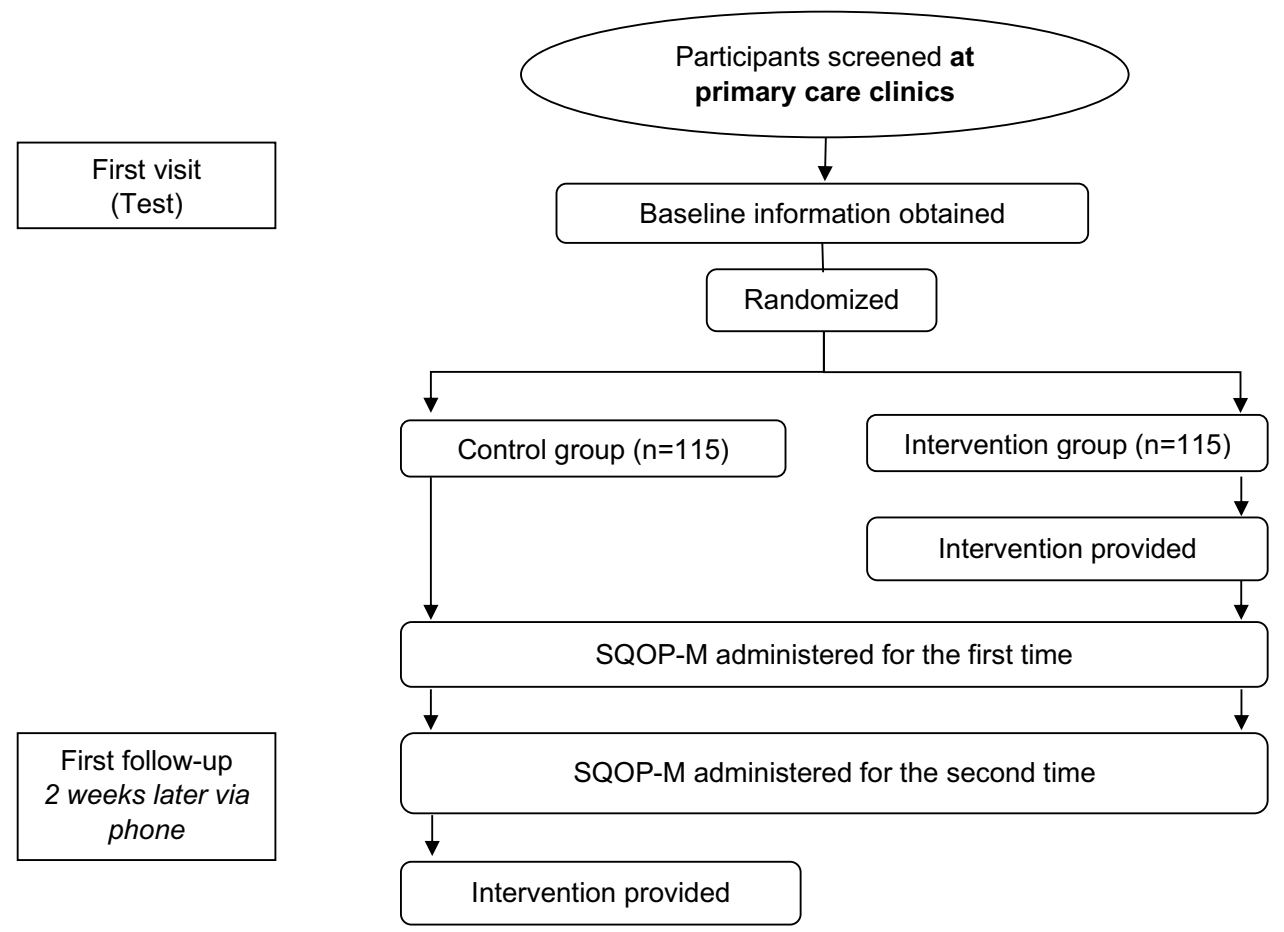

Figure 2 Randomized controlled trial process.

performed to explore the underlying relationships between the items as well as the appropriateness of the factor structure in the SQOP-M, as it is a new tool. ${ }^{28,29}$ The factors were extracted using the principal component analysis method and rotated using the maximum likelihood and promax methods. ${ }^{2,30}$ Factors with an eigenvalue of greater than 1 were retained. ${ }^{2,30}$

\section{Validity}

Discriminative validity was assessed to determine if the SQOP-M could differentiate between responses from the control group and the intervention group. We hypothesized that the responses provided by both groups would be different, with intervention group scoring higher than the control group. To assess discriminative validity between both groups, the chi square test was used on categorical data of the individual items while the Mann Whitney $U$-test was used for continuous data of individual items and total domain scores. ${ }^{31}$

\section{Reliability}

The internal reliability of the SQOP-M was assessed using Cronbach alpha because it is used to measure internal consistency for measures with Likert scales. ${ }^{32,33}$ Cronbach alpha values can be interpreted as: $\geq 0.80$ - high internal reliability, $\geq 0.51-0.79$ - adequate internal reliability, $\leq 0.50$ - low internal reliability. ${ }^{34,35}$

Test-retest was assessed using the kappa measure of agreement (to define inter-rater reliability). ${ }^{36}$ Kappa values were assessed as the following: 0.01-0.20- slight agreement, $0.21-$ 0.40- fair agreement, $0.41-0.60$ - moderate agreement, $0.61-$ 1.00 - substantial to almost perfect agreement. ${ }^{37,38}$ Wilcoxon signed rank test was used to assess continuous data of individual items and total domain scores for a difference between the patient group scores at test and retest.

\section{Results}

A total of 230/348 patients agreed to participate in this study (response rate $=66.1 \%$ ) (control group $=115$, intervention group=115). At retest, 82 (20.0\%) patients could not be contacted. Hence, only 184 patients were included at retest (control group $=98$, intervention group $=86$, response rate $=80.0 \%$ ).

The demographic characteristics of the patients in this study are displayed in Table 1. Patients in both control and intervention groups shared the same median age of 64 years and similar characteristics for weight and income level. However, the level of education between both groups was significantly different with the intervention group having a far higher number of patients who were 
diploma holders or tertiary-level educated (50.5\%) in comparison to control group $(32.2 \%)$.

\section{Psychometric Properties of the Malay Satisfaction Questionnaire for Osteoporosis Prevention (SQOP-M)} Factor Analysis

The factor loading of items in the SQOP-M is shown in Table 2 .

EFA extracted four domains with a criterion of eigenvalue $>1.0$. These were similar to the domains extracted for the English SQOP. ${ }^{2}$ The factor loading of the items ranged from $0.019-0.950$. Three items had a factor loading of $<0.3$.

Item number 17 in the SQOP-M was excluded from factor loadings calculation as it was an optional question. Patients were asked in item number 16 if they would like to pay for a pharmacist service in osteoporosis prevention counselling. Item number 17 was then provided as an optional question to those that answered "Yes" for item number 16, where patients were allowed to select how much they would like to pay for a service like this. Many patients did not answer this question as they felt that this pharmacist service should be free.

\section{Validity}

The discriminative validity of the SQOP-M is shown in Table 3.

The overall total satisfaction score for patients in the intervention group was significantly higher than the control group [76.9 (47.6-53.9) vs 50.4 (47.6-53.9), $\mathrm{p}<0.001]$. The intervention group scored significantly higher than the control group in all domains except the accessibility/convenience domain where the satisfaction scores were the same for both groups. The intervention group also scored significantly higher for 13/23 items of the SQOP-M.

Table I Baseline Demographic Characteristics of Participants for the Malay Satisfaction Questionnaire for Osteoporosis Patients (SQOP-M)

\begin{tabular}{|c|c|c|c|c|c|}
\hline Characteristics & Total $(n=230)$ & Control $(n=115)$ & $\begin{array}{l}\text { Intervention } \\
(n=I \mid 5)\end{array}$ & $\begin{array}{l}X^{2} I \\
Z-\text { Value }^{\#}\end{array}$ & $P$-value \\
\hline Median age (years) [IQR] & $64.0[50.0-82.0]$ & $64.0[50.0-79.0]$ & $64.0[50.0-82.0]$ & -0.081 & 0.935 \\
\hline \multicolumn{6}{|l|}{ Age range (years) [n (\%)] } \\
\hline$<65$ & $122(53.0)$ & $61(53.0)$ & $61(53.0)$ & & \\
\hline$\geq 65$ & $108(47.0)$ & $54(47.0)$ & $54(47.0)$ & & \\
\hline Median BMI $\left(\mathrm{kg} / \mathrm{m}^{2}\right)$ [IQR] & $25.5[16.1-43.3]$ & $26.2[17.8-43.3]$ & $25.0[16.1-40.2]$ & 1.026 & 0.693 \\
\hline \multicolumn{6}{|l|}{ BMI $\left(\mathrm{kg} / \mathrm{m}^{2}\right)$ [n (\%)] } \\
\hline$\leq \mathrm{I} 8.4$ (underweight) & $6(2.6)$ & $2(1.7)$ & $4(3.5)$ & & \\
\hline I8.5-24.9 (normal) & $102(44.3)$ & $50(43.5)$ & $52(45.2)$ & & \\
\hline 25.0-29.9 (overweight) & $72(31.3)$ & $36(31.3)$ & $36(31.3)$ & & \\
\hline$\geq 30.0$ (obese) & $50(21.7)$ & $27(23.5)$ & $23(20.0)$ & & \\
\hline Level of education [n (\%)] & & & & 10.068 & $0.039 *$ \\
\hline Primary (6 years of education) & $30(13.0)$ & $18(15.7)$ & $12(10.4)$ & & \\
\hline Secondary (II-13 years of education) & $105(45.7)$ & $60(52.2)$ & $45(39.1)$ & & \\
\hline $\begin{array}{l}\text { Diploma/Technical school training (12-14 years of } \\
\text { education) }\end{array}$ & 48 (20.9) & $22(19.1)$ & $26(22.6)$ & & \\
\hline Tertiary/Postgraduate (15-2| years of education) & $47(20.4)$ & $15(13.1)$ & $32(27.9)$ & & \\
\hline Income per month [n (\%)] & & & & 4.872 & 0.432 \\
\hline$<$ RMI000 (\$24I.I) & $36(15.7)$ & $19(16.5)$ & $17(14.8)$ & & \\
\hline RMI000-1999 (\$24I.I-482) & $69(30.0)$ & $40(34.8)$ & $29(25.2)$ & & \\
\hline RM2000-2999 (\$482.2-723.1) & $49(21.3)$ & $21(18.3)$ & $28(24.3)$ & & \\
\hline RM3000-3999 (\$723.3-964.2) & $27(11.7)$ & $12(10.4)$ & $15(13.0)$ & & \\
\hline RM4000-4999 (\$964.4-1205.3) & $19(8.3)$ & II (9.6) & $8(7.0)$ & & \\
\hline >RM5000 (\$1205) & $30(13.0)$ & $12(10.4)$ & $18(15.7)$ & & \\
\hline
\end{tabular}

Notes: ${ }^{\#}$ The chi-square test was used for all categorical variables, whilst the Mann-Whitney U-test was used for all continuous variables. $*$ Statistically significant at $\mathrm{p}<0.05$. Abbreviations: S. D., standard deviation; BMI, body mass index; \$, US dollar. 
Table 2 Factor Loadings of Items in the SQOP-M

\begin{tabular}{|c|c|c|c|c|c|c|c|c|}
\hline \multirow[t]{2}{*}{ No. } & \multirow[t]{2}{*}{ Item } & \multirow[t]{2}{*}{ Domains } & \multicolumn{4}{|c|}{ Factor Loadings } & \multirow{2}{*}{$\begin{array}{l}\text { Floor } \\
\text { Effect } \\
(\%)\end{array}$} & \multirow{2}{*}{$\begin{array}{l}\text { Ceiling } \\
\text { Effect } \\
(\%)\end{array}$} \\
\hline & & & $\mathbf{I}$ & 2 & 3 & 4 & & \\
\hline 19 & Explanation of osteoporosis & $\begin{array}{l}\text { Technical } \\
\text { Quality }\end{array}$ & 0.950 & & & & 0.03 & 0.92 \\
\hline 23 & Osteoporosis booklet provided & & 0.949 & & & & 0.03 & 0.95 \\
\hline 20 & Explanation of consequences of untreated osteoporosis & & 0.946 & & & & 0.03 & 0.88 \\
\hline 21 & $\begin{array}{l}\text { Explanation on how osteoporosis can be prevented via } \\
\text { lifestyle change(s) }\end{array}$ & & 0.945 & & & & 0.03 & 0.93 \\
\hline 22 & Explanation on the available methods to screen for osteoporosis & & 0.945 & & & & 0.03 & 0.93 \\
\hline 12 & Pharmacist in other hospitals should ___ this service & & 0.807 & & & & 0.00 & 0.37 \\
\hline 8 & How would you rate the advice given by the pharmacist? & & 0.709 & & & & 0.00 & 0.23 \\
\hline 7 & How would you rate the service provided by the pharmacist? & & 0.659 & & & & 0.01 & 0.25 \\
\hline 6 & Was the pharmacist easy to talk to? & & 0.656 & & & & 0.01 & 0.38 \\
\hline 9 & $\begin{array}{l}\text { How would you rate the overall quality of service that was } \\
\text { given by the pharmacist to you? }\end{array}$ & & 0.652 & & & & 0.00 & 0.20 \\
\hline 10 & This pharmacist service should ___. & & 0.644 & & & & 0.00 & 0.36 \\
\hline 15 & $\begin{array}{l}\text { How would you rate the amount of information provided } \\
\text { on the exercises to help strengthen bones? }\end{array}$ & $\begin{array}{l}\text { Outcomes/ } \\
\text { Efficacy }\end{array}$ & & 0.628 & & & 0.16 & 0.02 \\
\hline 14 & $\begin{array}{l}\text { How would you rate the amount of information provided to } \\
\text { change your diet to prevent bone loss? }\end{array}$ & & & 0.597 & & & 0.25 & 0.00 \\
\hline 13 & $\begin{array}{l}\text { How would you rate the amount of information provided to } \\
\text { prevent falls? }\end{array}$ & & & 0.528 & & & 0.24 & 0.03 \\
\hline 18 & How would you rate your understanding of osteoporosis now? & & & 0.460 & & & 0.00 & 0.07 \\
\hline 2 & $\begin{array}{l}\text { During the session, what did you think about the time given } \\
\text { to discuss your problems with the pharmacist? }\end{array}$ & $\begin{array}{l}\text { Accessibilityl } \\
\text { Convenience }\end{array}$ & & & 0.387 & & 0.83 & 0.03 \\
\hline 4 & How would you rate the comfort of the location? & & & & 0.331 & & 0.35 & 0.00 \\
\hline I & The service was conducted at a time that ___ for you & & & & 0.019 & & 0.00 & 0.55 \\
\hline 16 & Would you pay for a pharmacist counselling service? & $\begin{array}{l}\text { Interpersonal } \\
\text { relationship }\end{array}$ & & & & 0.763 & 0.86 & 0.04 \\
\hline II & $\begin{array}{l}\text { What do you think about having the same pharmacist to see } \\
\text { you for subsequent osteoporosis care? }\end{array}$ & & & & & 0.531 & 0.55 & 0.35 \\
\hline 5 & $\begin{array}{l}\text { If you have questions about osteoporosis, would you ask the } \\
\text { pharmacist? }\end{array}$ & & & & & 0.069 & 0.44 & 0.11 \\
\hline 3 & How would you rate the location of this service? & & & & & 0.049 & 0.48 & 0.01 \\
\hline
\end{tabular}

Note: Item 17 was an optional question; hence it was excluded from the factor loadings calculation.

Hence, similarly to the English SQOP, the SQOP-M was able to discriminate between a group with higher satisfaction and lower satisfaction. It also demonstrated that the intervention had an effect on the patient's satisfaction levels.

\section{Reliability}

The reliability of the SQOP-M is shown in Table 4.

Cronbach's alpha was calculated for each domain which ranged from 0.230 to 0.938 . Five out of 30 
Table 3 Discriminative Validity of Satisfaction Scores of the Control and Intervention Groups at Test for SQOP-M

\begin{tabular}{|c|c|c|c|c|c|c|}
\hline \multirow[t]{2}{*}{ Domain } & \multirow[t]{2}{*}{ Item Number } & \multicolumn{2}{|c|}{ Control Group $(n=\mid 15)$} & \multicolumn{2}{|c|}{ Intervention Group $(n=|| 5)$} & \multirow{2}{*}{$\begin{array}{c}\text { Chi }^{2} \text { Test/Mann-Whitney } \\
\text { U-Test }\end{array}$} \\
\hline & & Mean \pm SD & Median [IQR] & Mean \pm SD & Median [IQR] & \\
\hline Technical & 19 & $1.69 \pm 0.86$ & 1.00 & $4.85 \pm 1.05$ & 5.00 & $<0.001^{*}$ \\
\hline \multirow[t]{11}{*}{ Quality } & 23 & $1.39 \pm 0.66$ & 1.00 & $4.92 \pm 1.20$ & 5.00 & $<0.00 I^{*}$ \\
\hline & 20 & $1.60 \pm 0.77$ & 1.00 & $4.78 \pm 1.05$ & 5.00 & $<0.00 I^{*}$ \\
\hline & 21 & $1.41 \pm 0.66$ & 1.00 & $4.86 \pm 1.04$ & 5.00 & $<0.00 I^{*}$ \\
\hline & 22 & $1.49 \pm 0.67$ & 1.00 & $4.88 \pm 1.05$ & 5.00 & $<0.00 I^{*}$ \\
\hline & 12 & $3.28 \pm 0.47$ & 3.00 & $4.64 \pm 0.64$ & 5.00 & $<0.00 I^{*}$ \\
\hline & 8 & $3.65 \pm 0.62$ & 4.00 & $4.45 \pm 0.52$ & 4.00 & $<0.001 *$ \\
\hline & 7 & $3.67 \pm 0.75$ & 4.00 & $4.45 \pm 0.61$ & 4.00 & $<0.00 I^{*}$ \\
\hline & 6 & $3.69 \pm 0.80$ & 4.00 & $4.64 \pm 0.69$ & 5.00 & $<0.001 *$ \\
\hline & 9 & $3.31 \pm 0.65$ & 3.00 & $4.28 \pm 0.63$ & 4.00 & $<0.00 I^{*}$ \\
\hline & 10 & $3.97 \pm 0.34$ & 4.00 & $4.63 \pm 0.63$ & 5.00 & $<0.00 I^{*}$ \\
\hline & $\begin{array}{l}\text { Domain score } \\
\text { (\%) }\end{array}$ & $53.00 \pm 5.58$ & $\begin{array}{c}54.55[36.36- \\
65.45]\end{array}$ & $\begin{array}{l}94.18 \pm \\
11.87\end{array}$ & $\begin{array}{c}96.36 \text { [45.45- } \\
98.98]\end{array}$ & $<0.001 *$ \\
\hline Outcomes/ & 15 & $2.56 \pm 1.52$ & 4.00 & $3.86 \pm 0.54$ & 4.00 & $<0.00 I^{*}$ \\
\hline \multirow[t]{4}{*}{ Efficacy } & 14 & $2.52 \pm 1.47$ & 2.00 & $3.67 \pm 0.83$ & 4.00 & $<0.001 *$ \\
\hline & 13 & $2.95 \pm 1.43$ & 4.00 & $3.80 \pm 0.69$ & 4.00 & $<0.00 I^{*}$ \\
\hline & 18 & $3.83 \pm 0.38$ & 4.00 & $4.02 \pm 0.50$ & 4.00 & $<0.00 I^{*}$ \\
\hline & $\begin{array}{l}\text { Domain score } \\
(\%)\end{array}$ & $\begin{array}{l}59.26 \pm \\
18.7 \mid\end{array}$ & $\begin{array}{c}65.00[30.00- \\
85.00]\end{array}$ & $76.74 \pm 7.23$ & $\begin{array}{c}80.00[55.00- \\
85.00]\end{array}$ & $<0.00 I^{*}$ \\
\hline Accessibility/ & 2 & $1.35 \pm 0.90$ & 1.00 & $1.34 \pm 0.95$ & 1.00 & 0.335 \\
\hline \multirow[t]{3}{*}{ Convenience } & 4 & $2.30 \pm 0.76$ & 2.00 & $1.52 \pm 0.87$ & 1.00 & $<0.001 *$ \\
\hline & I & $3.37 \pm 1.25$ & 4.00 & $4.84 \pm 0.49$ & 5.00 & $<0.001 *$ \\
\hline & $\begin{array}{l}\text { Domain score } \\
\text { (\%) }\end{array}$ & $\begin{array}{l}46.84 \pm \\
10.72\end{array}$ & $\begin{array}{c}46.67[26.67- \\
86.67]\end{array}$ & $51.36 \pm 8.28$ & $\begin{array}{c}46.67[26.67- \\
73.33]\end{array}$ & $<0.001 *$ \\
\hline Interpersonal & 16 & $1.34 \pm 1.03$ & 1.00 & $1.54 \pm 1.21$ & 1.00 & 0.224 \\
\hline \multirow[t]{5}{*}{ Relationship } & 11 & $2.19 \pm 1.73$ & 1.00 & $3.05 \pm 1.93$ & 4.00 & $<0.00 I^{*}$ \\
\hline & 5 & $3.34 \pm 1.24$ & 4.00 & $1.94 \pm 1.60$ & 1.00 & $<0.001 *$ \\
\hline & 3 & $1.19 \pm 0.62$ & 1.00 & $3.12 \pm 1.12$ & 4.00 & $<0.001 *$ \\
\hline & $\begin{array}{l}\text { Domain score } \\
(\%)\end{array}$ & $\begin{array}{l}37.61 \pm \\
14.18\end{array}$ & $\begin{array}{c}40.00[20.00- \\
40.00]\end{array}$ & $51.85 \pm 8.93$ & $\begin{array}{c}55.56[33.33- \\
77.78]\end{array}$ & $<0.00 I^{*}$ \\
\hline & Total score (\%) & $50.64 \pm 4.93$ & $\begin{array}{c}50.43[47.61- \\
53.91]\end{array}$ & $75.94 \pm 5.90$ & $\begin{array}{c}76.92[51.28- \\
84.62]\end{array}$ & $<0.001 *$ \\
\hline
\end{tabular}

Notes: Item 17 was an optional question; hence it was excluded. ${ }^{\#} \mathrm{Chi}^{2}$ test was used for categorical variables while the Mann-Whitney $U$-test was used for continuous variables; *Statistically significant at $p<0.05$.

items had corrected item-total correlations $<0.2$. The Kappa measurement of agreement values ranged from $0.124-0.627$, where $2 / 23(8.7 \%)$ items were in substantial agreement, $8 / 23(34.8 \%)$ items were in moderate agreement, $7 / 23$ (30.4\%) items were in fair agreement and 5/23 (21.7\%) items were in slight agreement. Four out of 23 items had Wilcoxon signed rank test values that were statistically significant, $\mathrm{p}<0.005$. As item 17 was an optional question, it was excluded from the analysis.

\section{Discussion}

The SQOP-M had adequate psychometric properties and was able to significantly discriminate between the satisfaction scores of the patients in the control and intervention groups. The SQOP-M also performed similarly to the English SQOP. ${ }^{2}$

Demographically, the patients for both studies showed similar distribution in weight characteristics though SQOP-M participants were older with a median age of 64 years while patients for SQOP had a median age of 56 


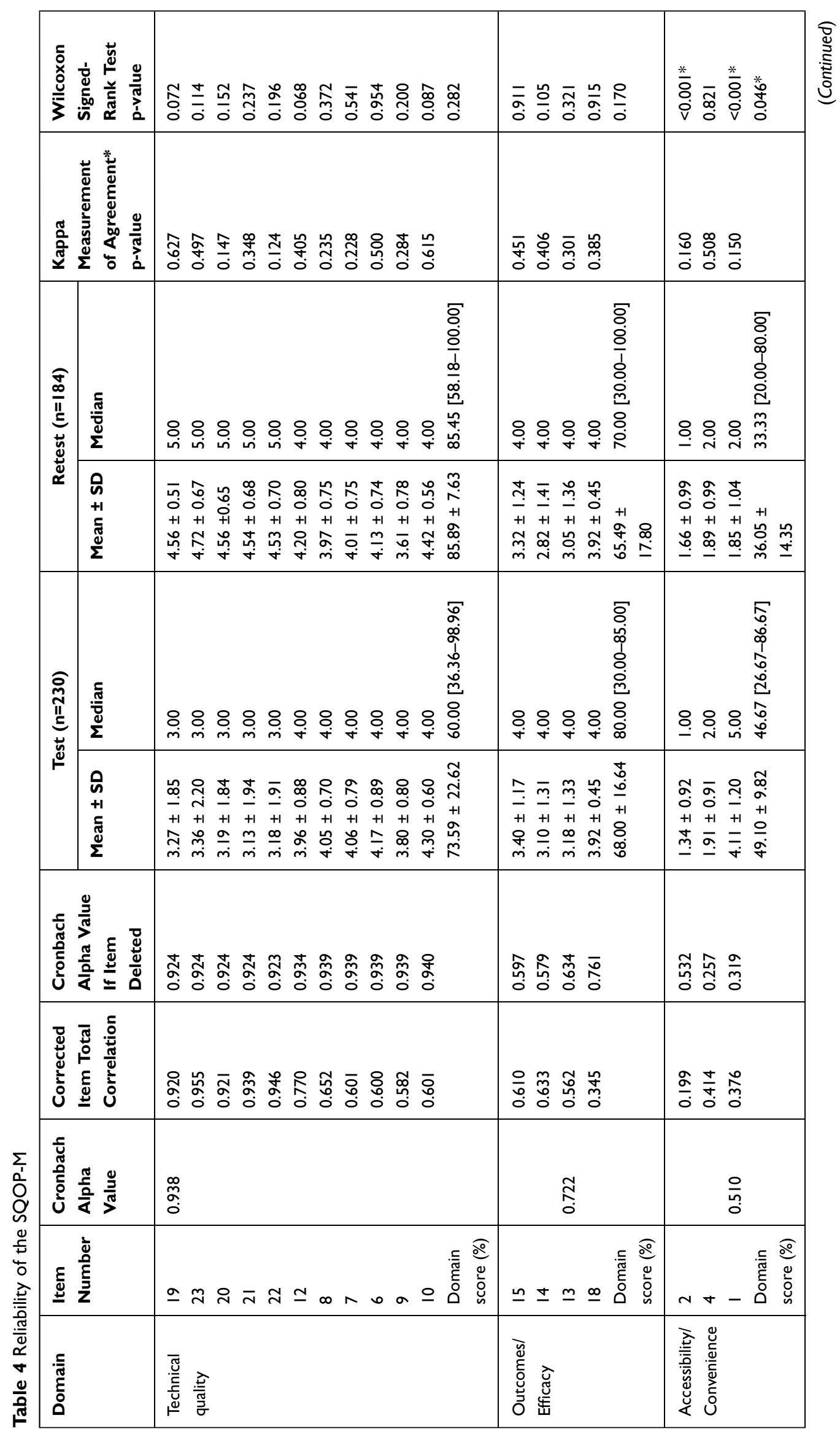




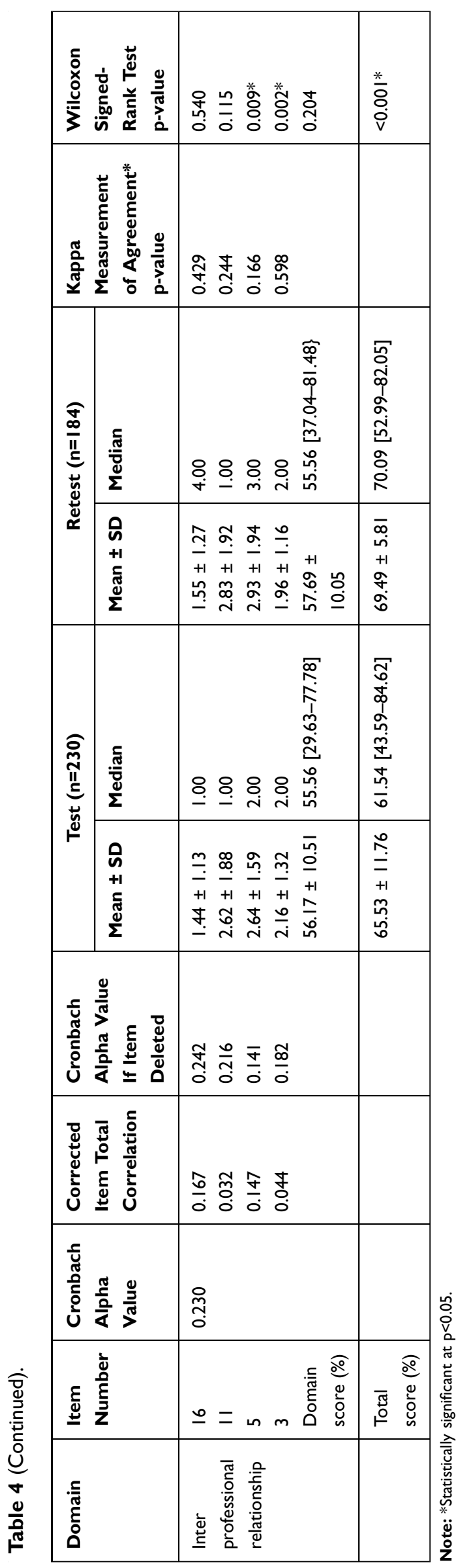

years. ${ }^{2}$ Patients in the intervention group for SQOP-M also had significantly higher education levels than control groups. Previous research indicates that older patients tend to be more satisfied while highly educated patients tend to be less satisfied with the health-care services provided. ${ }^{39-43}$ However, in this study regression analyses were not performed to show a link between variable and outcome as the aim of the study was to cross-culturally adapt and validate the SQOP-M.

EFA showed that there were four domains of satisfaction being measured within the SQOP-M to assess patients' satisfaction towards osteoporosis prevention services in Malaysia. This differed to the SQOP which had been initially designed to extract seven domains. ${ }^{2}$ However, the SQOP-M extracted similar domains to the SQOP which were deemed significant based on themes from a previous qualitative study that the SQOP was developed to address. ${ }^{44}$ In comparison to domains measured by other satisfaction tools, there were similarities in the domains of convenience. However, it was difficult to compare all these tools as the premise of the SQOP-M was to measure satisfaction at osteoporosis prevention instead of treatment. The SQOP-M was also meant to mirror the SQOP, therefore no changes were made. Overall, The SQOP-M performed satisfactorily in the EFA indicating that it is suitable to assess patients' satisfaction towards osteoporosis prevention services in Malaysia together with the SQOP.

The intervention group scored significantly higher than the control group for all items of the SQOP-M except in four items (item 2=During the session, what did you think about the time given to discuss your problems with the pharmacist?; item $4=$ How would you rate the comfort of the location?; item 5=If you have questions about osteoporosis, would you ask the pharmacist?; and item $16=$ Would you pay for a pharmacist counselling service?), which could be due to several reasons. Many patients expressed positively that they were satisfied at receiving counselling from the pharmacist but felt pharmacists should play a more prominent role in providing counselling sessions to improve their knowledge on health. However, patients still felt more comfortable discussing their health-related issues with their doctor as they were not used to having these types of conversations with a pharmacist whose core role was thought to be in supply of medications. Patients also expressed that having greater privacy and less background noise would have improved their satisfaction experience overall. A majority of patients 
also felt that counselling on health is an important service that should be provided freely to all. Overall, total satisfaction score for patients in the intervention group was significantly higher than the control group indicating that the SQOP-M was able to perform satisfactorily to discriminate between higher and lower satisfaction scores.

Cronbach's alpha values were lowest for the "interpersonal relationship" and "accessibility/convenience" domains as these were the smallest domains containing less than four items. For the SQOP, the Cronbach alpha for the interpersonal relationship domain had not been calculated as it was considered too small. ${ }^{2}$ Five items with corrected item-total correlations $<0.2$ were retained because excluding any of these items did not improve the overall Cronbach's alpha value significantly. Overall, these domains and items were retained to maintain the similarity between the SQOP-M and the SQOP.

The Kappa measurement of agreement values were in slight agreement for $5 / 23$ items. Three out of these items had Wilcoxon signed rank test values that were statistically significant, $\mathrm{p}<0.005$ as patients were not "satisfied" that the SQOP-M was administered in a noisy clinic waiting room. Providing a private, consultation area or allocating a booth to the pharmacist for counselling purposes may result in improved patient satisfaction. ${ }^{45-47}$ During administration of SQOP-M at both test and retest, patients expressed preference for discussing health issues with a doctor rather than a pharmacist which may indicate a need for pharmacists in Malaysia to embrace more patient-centered roles with a clinical focus at a primary care level in order to increase profile recognition amongst community-dwelling patients. ${ }^{48,49}$ Patients may have been less satisfied with counselling on items 20 and 22, as the emphasis of the counselling session was on osteoporosis prevention. Hence, future counselling sessions should reflect this by educating patients on all aspects of osteoporosis equally. Overall, the SQOP-M performed satisfactorily at test-retest, indicating that the SQOP-M achieved stable reliability.

A limitation of this study as highlighted in the SQOP is that it was specifically designed to measure the satisfaction of patients towards an osteoporosis prevention service conducted by a pharmacist. ${ }^{2}$ As a result, there are six items within the questionnaire worded specifically to assess the satisfaction of a pharmacist providing the service. No changes were made to the SQOP-M as it was meant to mirror the SQOP. However, minor modifications may need to be made to both the SQOP and the SQOP-M if it is used to assess osteoporosis prevention service satisfaction provided by other health care professionals. ${ }^{2}$ This study was also administered using different modes where patients answered the SQOP-M themselves at test but it was later readministered over the telephone at retest. ${ }^{50}$ This was carried out to minimize patient inconvenience in presenting physically to the clinic multiple times to answer the questionnaire as well as to maximize response rates. ${ }^{50}$ The patients may have answered the items differently due to different modes of administration. However, as this would have been applicable to all participants in the study, its impact on the validation process would be negated. ${ }^{26,50,51}$

\section{Conclusion}

The Malay Satisfaction Questionnaire for Osteoporosis Prevention (SQOP-M) was found to be a reliable and valid instrument to assess patient satisfaction on osteoporosis prevention services amongst Malay-speaking patients in Malaysia. It can be used together with the English version of the SQOP to assess the effectiveness of osteoporosis-related prevention services amongst the wider Malaysian population.

\section{Data Sharing Statement}

All data generated or analyzed during this study are included in this published article.

\section{Ethics Approval}

This study was approved by the Medical Research Ethics Committee of University Malaya Medical Centre (MREC ID NO: 2018115-5959) and the Medical Research Ethics Committee, Ministry of Health Malaysia (NMRR-181302-40112). This study was conducted in accordance with the Declaration of Helsinki.

\section{Consent to Participate}

Written informed consent was obtained from all individual participants included in the study.

\section{Consent for Publication}

The participants signed informed consent regarding publishing their data.

\section{Acknowledgments}

We wish to thank the research assistants involved in the data collection stages of this study and all the patients who 
participated in this study. We would also like to thank all the authors whose articles are referenced in our study.

\section{Funding}

This study was funded by the University Malaya Research Grant (RP048C-17HTM).

\section{Disclosure}

The authors declare that they have no conflict of interest.

\section{References}

1. White B. Measuring patient satisfaction: how to do it and why to bother. Fam Pract Manag. 1999;6(1):40-44.

2. Toh LS, Lai PSM, Wu DBC, et al. The development and validation of the satisfaction questionnaire for osteoporosis prevention in Malaysia. Patient Prefer Adherence. 2014;8:1-17.

3. Prakash B. Patient satisfaction. J Cutan Aesthet Surg. 2010;3 (3):151-155. doi:10.4103/0974-2077.74491

4. Palacios S, Agodoa I, Bonnick S, et al. Treatment satisfaction in postmenopausal women suboptimally adherent to bisphosphonates who transitioned to denosumab compared with risedronate or ibandronate. J Clin Endocrinol Metab. 2015;100(3):E487-92. doi:10.1210/jc.2014-3594

5. Barrett-Connor E, Wade SW, Do TP, et al. Treatment satisfaction and persistence among postmenopausal women on osteoporosis medications: 12-month results from POSSIBLE US ${ }^{\mathrm{TM}}$. Osteoporos Int. 2012;23(2):733-741. doi:10.1007/s00198-011-1620-3

6. Lim P, Ong F, Adeeb N, et al. Bone health in urban midlife malaysian women: risk factors and prevention. Osteoporos Int. 2005;16 (12):2069-2079. doi:10.1007/s00198-005-2003-4

7. Janiszewska M, Firlej E, Zolnierczuk-Kieliszek D, Dziedzic M. Knowledge about osteoporosis prevention among women screened by bone densitometry. Prz Menopauzalny. 2016;15(2):96-103. doi: $10.5114 / \mathrm{pm} .2016 .61192$

8. Levine JP. Identification, diagnosis and prevention of osteoporosis. Am J Manag Care. 2011;17(6):170-176.

9. Cauley JA. Public health impact of osteoporosis. J Gerentol. 2013;68 (10):1243-1251. doi:10.1093/gerona/glt093

10. Chuah P, Nurul Z, Chuan J, et al. Association between risk factors of osteoporosis and bone mineral density in women of different ethnic groups in a Malaysian hospital. Int J Obes Relat Metab Disord. 2014;7(1):1-11.

11. Cheung CL, Ang SB, Chadha M, et al. An updated hip fracture projection in Asia: the Asian Federation of Osteoporosis Societies Study. Osteoporos Sarcopenia. 2018;4(1):16-21. doi:10.1016/j.afos.2018.03.003

12. Mithal A, Ebeling P, Kyer CS. Epidemiology, Costs \& Burden of Osteoporosis in 2013. Singapore: International Osteoporosis Foundation; 2013.

13. Yeap SS, Hew FL, Damodaran P, et al. A summary of the Malaysian clinical guidance on the management of postmenopausal and male osteoporosis, 2015. Osteoporos Sarcopenia. 2016;2(1):1-12. doi:10. 1016/j.afos.2016.02.004

14. Des Bordes J, Prasad S, Pratt G, Suarez-Almazor ME, Lopez-Olivo MA. Knowledge, beliefs, and concerns about bone health from a systematic review and metasynthesis of qualitative studies. PLoS One. 2020;15(1):1-17. doi:10.1371/journal.pone.0227765

15. Oh EG, Lee JE, Yoo JY. A systematic review of the effectiveness of lifestyle interventions for improving bone health in women at high risk of osteoporosis. JBI Libr Syst Rev. 2012;10(30):1734-1784.

16. Kling JM, Clarke BL, Sandhu NP. Osteoporosis prevention, screening, and treatment: a review. J Womens Health. 2014;23(7):563-572. doi:10.1089/jwh.2013.4611
17. Flood EM, Beusterien KM, Green H, et al. Psychometric evaluation of the Osteoporosis Patient Treatment Satisfaction Questionnaire (OPSAT-Q), a novel measure to assess satisfaction with biphosphonate treatment in postmenopausal women. Health Qual Life Outcomes. 2006;4(1):1-9. doi:10.1186/1477-7525-4-42

18. Gold DT, Horne R, Coon CD, et al. Development, reliability, and validity of a new preference and satisfaction questionnaire. Value Health. 2011;14(8):1109-1116. doi:10.1016/j.jval.2011.06.010

19. Lai PSM, Chua SS, Chan SP, Low WY, Wong ICK. Development and validation of the osteoporosis patient satisfaction questionnaire (OPSQ). Mauritas. 2009;65(1):55-63.

20. Adelaar KA. Where does Malay come from? Twenty years of discussions about homeland, migrations and classifications. Bijdragen tot de Taal Land-en Volkenkunde. 2004;160(1):1-30. doi:10.1163/ 22134379-90003733

21. Wild D, Grove A, Martin M, et al. Principles of good practice for the translation and cultural adaptation process for the patient-reported outcomes (PRO) measures: report of the ISPOR task force for translation and cultural adaptation. Value Health. 2005;8(2):94-104. doi:10.1111/j.1524-4733.2005.04054.x

22. Leonard-Kempf K. Encyclopedia of social measurement; 2005. Available from: https://www.sciencedirect.com/science/reference works/9780123693983. Accessed June 3, 2021.

23. Pearson R, Mundform D. Recommended sample size for conducting exploratory factor analysis on dichotomous data. J Mod Appl Stat Methods. 2010;9(2):359-368. doi:10.22237/jmasm/1288584240

24. Lai PSM, Sandhu AK. Anda Boleh Mencegah Osteoporosis! Kuala Lumpur, Malaysia: Department of Primary Care Medicine, University of Malaya; 2018.

25. DeVon HA, Block ME, Moyle-Wright P, et al. A psychometric toolbox for testing validity and reliability. $J$ Nurs Scholarsh. 2007;39 (2):155-164. doi:10.1111/j.1547-5069.2007.00161.x

26. Toh LS, Lai PSM, Wu DB-C, Wong KT, Low BY, Anderson C. The development and validation of the Osteoporosis Prevention and Awareness Tool (OPAAT) in Malaysia. PLoS One. 2015;1-19.

27. Knekta E, Runyon C, Eddy S. One size doesn't fit all: using factor analysis to gather validity evidence when using surveys in your research. CBE Life Sci Educ. 2019;18(1):1-17. doi:10.1187/cbe.1804-0064

28. Goretzko D, Pham TTH, Buhner M. Exploratory factor analysis: current use, methodological developments and recommendations for good practice. Curr Psychol. 2019;13.

29. Howard M. A review of exploratory factor analysis decisions and overview of current practices: what we are doing and how can we improve? Int J Hum Comput Interact. 2016;32(1):51-62. doi:10.1080/10447318.2015.1087664

30. Green S, Salkind N. Using SPSS for Windows and Macintosh Analyzing and Understanding Data. 3rd ed. New Jersey, USA: Prentice Hall; 2003.

31. Du Prel JB, Rohrig B, Hommel G, Blettner M. Choosing statistical tests. Dtsch Arztebl Int. 2010;107(19):343-348. doi:10.3238/ arztebl.2010.0343

32. Adamson K, Prion S. Reliability: measuring internal consistency using Cronbach's alpha. Clin Simul Nurs. 2013;9(5):179-180. doi:10.1016/j.ecns.2012.12.001

33. Sarmah HK, Bora Hazarika B. Determination of reliability and validity measures of a questionnaire. Indian J Educ Inf Manag. 2012;1 (11):508-517.

34. Taber KS. The use of Cronbach's alpha when developing and reporting research instruments in science education. Res Sci Educ. 2018;48:1273-1296. doi:10.1007/s11165-016-9602-2

35. Sharma B. A focus on reliability in developmental research through Cronbach's alpha among medical, dental and paramedical professionals. Asian Pac J Health Sci. 2016;3(4):271-278. doi:10.21276/ apjhs.2016.3.4.43 
36. Boateng GO, Neilands TB, Frongillo EA, Melgar-Quinonez HR, Young SL. Best practices for developing and validating scales for health, social and behavioural research: a primer. Front Public Health. 2018;6:1-18. doi:10.3389/fpubh.2018.00149

37. McHugh ML. Interrater reliability: the kappa statistic. Biochem Med. 2012;22(3):276-282. doi:10.11613/BM.2012.031

38. Viera AJ, Garrett JM. Understanding interobserver agreement: the kappa statistic. Fam Med. 2005;37(5):360-363.

39. Rahmqvist M. Patient satisfaction in relation to age, health status and other background factors: a model for comparisons of care units. Int J Qual Health Care. 2001;13(5):385-390. doi:10.1093/intqhe/ 13.5.385

40. Rahmqvist M, Bara A. Patient characteristics and quality dimensions related to patient satisfaction. Int J Qual Health Care. 2010;22 (2):86-92. doi:10.1093/intqhe/mzq009

41. Crow R, Gage H, Hampson S, et al. The measurement of satisfaction with healthcare: implications for practice from a systematic review of the literature. Health Technol Assess. 2002;6(32):1-244. doi:10.3310/ hta6320

42. Bautista RED, Glen ET, Shetty NK. Factors associated with satisfaction with care among patients with epilepsy. Epilepsy Behav. 2007;11 (4):518-524. doi:10.1016/j.yebeh.2007.07.019

43. Jaipaul CK, Rosenthal GE. Are older patients more satisfied with hospital care than younger patients? J Gen Intern Med. 2003;18 (1):23-30. doi:10.1046/j.1525-1497.2003.20114.x
44. Ware JE Jr, Snyder MK, Wright WR, Davies AR. Defining and measuring patient satisfaction with medical care. Eval Program Plann. 1983;6(3-4):247-263. doi:10.1016/0149-7189(83)90005-8

45. Layqah L. The practice of counseling in pharmacy: patients' perspectives. J Anal Pharm Res. 2018;7(4):472-476. doi:10.15406/ japlr.2018.07.00269

46. Jacobs K. Patient satisfaction by design. Semin Hear. 2016;37 (4):316-324. doi:10.1055/s-0036-1593999

47. Lau ETL, Tan SH, Antwertinger YJ, Hall T, Nissen LM. Counseling interactions between patients living with persistent pain and pharmacists in Australia: are we on the same page? J Pain Res. 2019;12:2441-2455. doi:10.2147/JPR.S199017

48. Manning DH, Kristeller JL. Pharmacy transitions of care and culture. Hosp Pharm. 2017;52(8):520-521. doi:10.1177/0018578717724887

49. Ilardo ML, Speciale A. The community pharmacist: perceived barriers and patient-centered care communication. Int J Environ Res Public Health. 2020;17(2):1-16. doi:10.3390/ijerph17020536

50. Vogl S. Telephone versus face-to-face interviews: mode effect on semistructured interviews with children. Sociol Methodol. 2013;43 (1):133-177. doi:10.1177/0081175012465967

51. Check J, Schutt RK. Research Methods in Education. California, USA: Sage Publications; 2012.
Patient Preference and Adherence

\section{Publish your work in this journal}

Patient Preference and Adherence is an international, peer-reviewed, open access journal that focusing on the growing importance of patient preference and adherence throughout the therapeutic continuum. Patient satisfaction, acceptability, quality of life, compliance, persistence and their role in developing new therapeutic modalities and compounds to optimize clinical outcomes for existing disease

\section{Dovepress}

states are major areas of interest for the journal. This journal has been accepted for indexing on PubMed Central. The manuscript management system is completely online and includes a very quick and fair peer-review system, which is all easy to use. Visit http:// www.dovepress.com/testimonials.php to read real quotes from published authors. 